\title{
A CLINICAL STUDY ON KUMKUM AND BINDI DERMATITIS AND THEIR RELEVANCE TO PATCH TESTING
}

Venna Ashok Babu ${ }^{1}$, K. Sri Venkateswaran²

${ }^{1}$ Associate Professor, Department of Dermatology (DVL), Mamatha General Hospital, Khammam, Telangana.

${ }^{2}$ Professor and HOD, Department of DVL, Vinayaka Mission Medical College and Hospital, Karaikal, Pondicherry.

\section{ABSTRACT}

\section{BACKGROUND}

Applying kumkum and sticker bindi on the forehead and hair parting is universally followed by Hindu women as a traditional symbol. This tradition is more followed in south India, especially by married women as sindoor in hair parting. There are more complaints of itching, burning and redness on forehead and hair parting where sticker bindi and kumkum are applied in women attending dermatology outpatient department.

Aim of the study is to evaluate kumkum and sticker bindi dermatitis with relevance to patch testing.

\section{MATERIALS AND METHODS}

50 clinically suspected cases of dermatitis over forehead (Glabella) and hair parting were taken up for study. Patch testing was done with patients own kumkum, sticker bindi, turmeric allergen (As turmeric is used in the preparation of kumkum), nickel (as nickel is one of the major ingredients in sticker bindi).

\section{RESULTS}

Out of 50 cases tested, 38 patients (76\%) were positive for patch testing and results are statistically significant.

\section{CONCLUSION}

Dermatitis (allergic contact dermatitis) to kumkum, sticker bindi are proved by the patch testing. Kumkum and sticker bindi have a wide popularity among people as cosmetics and also for their traditional and religious beliefs. Application of them is inevitable in the community, so an alternative should be found (heated and dried kumkum which is non-allergenic). As the incidence of kumkum dermatitis is raising, we can think of inclusion of kumkum and turmeric in Indian standard series (ISS) of allergens.

\section{KEYWORDS}

Kumkum, Bindi, Dermatitis, Patch Test.

HOW TO CITE THIS ARTICLE: Babu VA, Venkateswaran KS. A clinical study on kumkum and bindi dermatitis and their relevance to patch testing. J. Evolution Med. Dent. Sci. 2016;5(94):6919-6923, DOI: 10.14260/jemds/2016/1566

\section{BACKGROUND}

Application of kumkum and sticker bindi on forehead, glabellar region is universally followed by Hindu women as a traditional symbol. Married women apply kumkum in the hair parting as sindoor as a religious custom. Complaints of itching, burning, vesiculation, pigmentation in and around these areas has increased in the recent past. Turmeric is used in the preparation of kumkum, the turmeric is dried and powered and mixed with a bit of slaked lime which turns the rich yellow power in to red colour.1, 2 Turmeric is known as golden spice of life. ${ }^{3}$ It has been used in India as a medicinal plant and held sacred from time immemorial. Turmeric contains 5\% of essential oils and up to $3 \%$ of curcumin, a polyphenol compound responsible for the yellow colour of turmeric and is the most active pharmacological agent. ${ }^{4}$ The active ingredient (curcumin) can be extracted by dissolving turmeric in

Financial or Other, Competing Interest: None.

Submission 20-10-2016, Peer Review 14-11-2016,

Acceptance 19-11-2016, Published 24-11-2016.

Corresponding Author:

Dr. Venna Ashok Babu,

H. No. 11-2-80/1,

Balaji Nagar, Wyra Road,

Khammam-507001.

E-mail: drashok24@gmail.com

DOI: $10.14260 /$ jemds/2016/1566 ethanol and evaporation of the solvent. ${ }^{5}$ Apart from allergic contact dermatitis, it can also cause pigmented contact dermatitis, lichen planus pigmentosus.

Sticker bindi is a synthetic fabric or plastic patch made up of circular discs of polyvinylchloride (PVC) and the adhesive material contains P-tertiary butyl phenol (PTBP).6, 7, 8 Other agents are epoxy resins, ${ }^{9}$ dispersible blue 124 , dispersible blue 106,10 nickel,11, thimerosal and gallate mix.12 Nickel in sticker bindi can cause allergic contact dermatitis. ${ }^{11}$ Sticker bindi can also cause contact leucoderma due to PTBP used as adhesive which is melanotoxic. ${ }^{13,14}$

The incidence of kumkum and sticker bindi dermatitis is increasing in the community, and the stigma due to hypopigmentation (contact leucoderma), hyperpigmentation and cosmetic disfigurement is high. Hence, we took up the study to assess the relevance of patch testing with these dermatitis and also to educate the patients regarding the dermatitis and necessary precautions to be taken to avoid dermatitis and further complications.

\section{MATERIALS AND METHODS}

This prospective clinical study comprised of 50 clinically suspected cases of dermatitis who were using both kumkum and sticker bindi over the glabellar region, forehead, hair parting of all age groups attending the dermatology outpatient department in Vinayaka Missions Medical College and Hospital from 15.10.2012 to 15.02.2014. 
A detailed history of the patients included in the study was taken. Complaints, duration, evolution, progress were noted. Morphology of the lesions and the sites of involvement were noted. Past history of allergies (atopy) were evaluated. History of topical application of any medicaments was noted. Additionally, routine general and systemic examination and routine blood investigation namely routine haemogram and blood sugar were done. Patients were taken for patch testing with patients' own kumkum, sticker bindi, turmeric (used in the preparation of kumkum), nickel (one of the ingredients in sticker bindi).

The patch test procedure and common side effects were explained to the patient and informed consent was taken in every case. Two sets of patches one with kumkum and turmeric, and other with sticker bindi and nickel were applied on the patients back. Patches were removed after 48 hours, readings were taken 45-60 minutes after removal of patches.

\section{Reading and Interpretations}

Recording of patch test reactions is done according to the International Contact Dermatitis Research Group (ICDRG)

- : Negative.

?+ : Doubtful reaction, faint erythema only.

+ : Weekly positive reaction, palpable erythema, infiltration, possible papules.

++ : Strong positive reaction, erythema, infiltration, papules and vesicles.

+++ : $\quad$ Extreme positive reaction, intense erythema and infiltration and coalescing vesicles.

IR : Irritant reaction.

NT : $\quad$ Not tested.

\section{RESULTS}

Out of 50 patients tested, $20(40 \%)$ patients were positive for kumkum and turmeric. 12 (24\%) patients were positive for kumkum, sticker bindi, turmeric and nickel. 6 (12\%) patients were positive for bindi and nickel.

\begin{tabular}{|c|c|c|c|}
\hline & Total & $\begin{array}{c}\text { Total Positive } \\
\text { Results }\end{array}$ & $\begin{array}{c}\text { Negative } \\
\text { Results }\end{array}$ \\
\hline $\begin{array}{c}\text { Number of } \\
\text { Patients (n) }\end{array}$ & 50 & 38 & 12 \\
\hline Percentage \% & 100 & $76 \%$ & $24 \%$ \\
\hline \multicolumn{3}{|c|}{ Table 1. Tested Patients (n) } \\
\hline
\end{tabular}

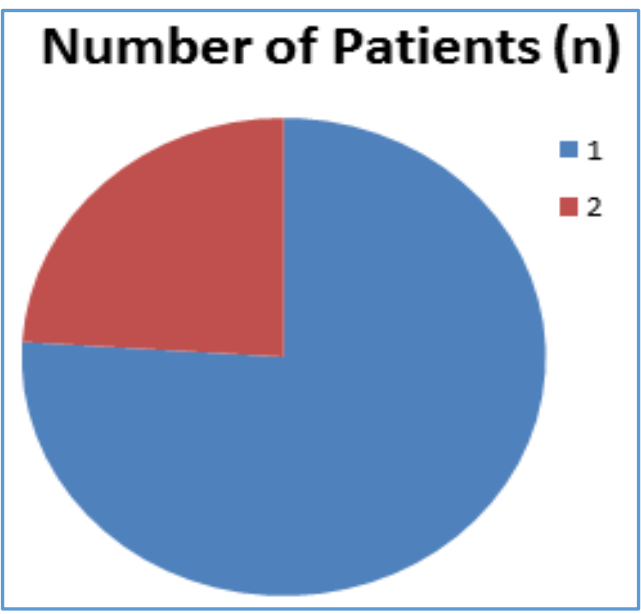

\begin{tabular}{|c|c|c|}
\hline Age Group & Total & $\mathbf{\%}$ \\
\hline 1-10 years & 2 & $4 \%$ \\
\hline 11-20 years & 5 & $10 \%$ \\
\hline $21-30$ years & 20 & $40 \%$ \\
\hline $31-40$ years & 13 & $26 \%$ \\
\hline 41-50 years & 6 & $12 \%$ \\
\hline 51-60 years & 4 & $8 \%$ \\
\hline Total & $\mathbf{5 0}$ & $\mathbf{1 0 0} \%$ \\
\hline Table 2. Age Distribution of the Patients \\
\hline \multicolumn{2}{|c}{}
\end{tabular}

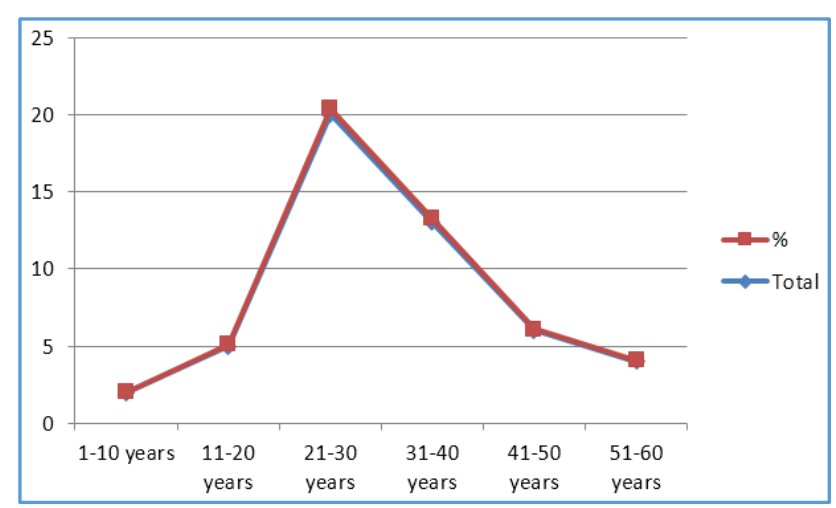

\begin{tabular}{|c|c|c|}
\hline Age Group & Kumkum \& Turmeric & $\mathbf{\%}$ \\
\hline 1-10 years & 0 & $0 \%$ \\
\hline 11-20 years & 2 & $4 \%$ \\
\hline 21-30 years & 10 & $20 \%$ \\
\hline 31-40 years & 5 & $10 \%$ \\
\hline 41-50 years & 2 & $4 \%$ \\
\hline 51-60 years & 1 & $2 \%$ \\
\hline Total & 20 & $40 \%$ \\
\hline \multicolumn{2}{|r|}{ Table 3. Age Distribution of Positive } \\
Cases for Kumkum and Turmeric \\
\hline
\end{tabular}

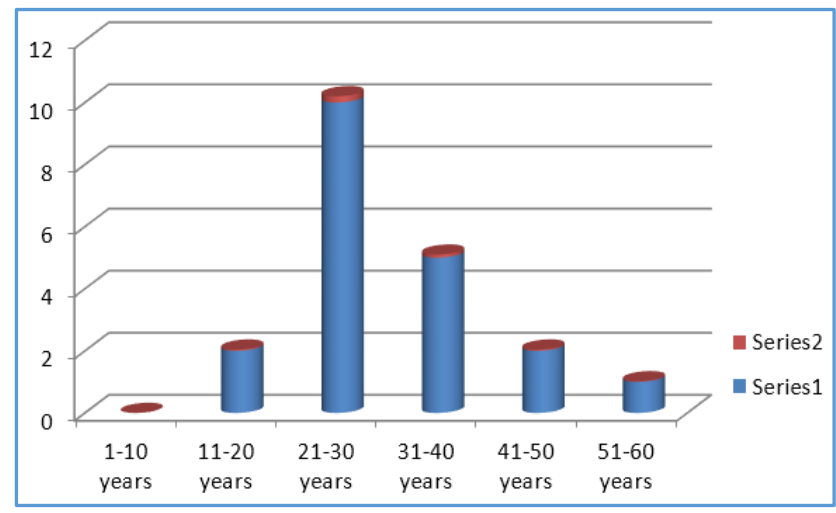

\begin{tabular}{|c|c|c|}
\hline $\begin{array}{l}\text { Age } \\
\text { Group }\end{array}$ & $\begin{array}{c}\text { Kumkum, Turmeric, } \\
\text { Sticker Bindi and Nickel }\end{array}$ & $\%$ \\
\hline $1-10$ years & 0 & $0 \%$ \\
\hline $11-20$ years & 1 & $2 \%$ \\
\hline 21-30 years & 4 & $8 \%$ \\
\hline $31-40$ years & 6 & $12 \%$ \\
\hline $41-50$ years & 0 & $0 \%$ \\
\hline 51-60 years & 1 & $2 \%$ \\
\hline Total & 12 & $24 \%$ \\
\hline \multicolumn{3}{|c|}{$\begin{array}{l}\text { Table 4. Age Distribution of Positive Cases for } \\
\text { Kumkum, Turmeric, Sticker Bindi and Nickel }\end{array}$} \\
\hline
\end{tabular}




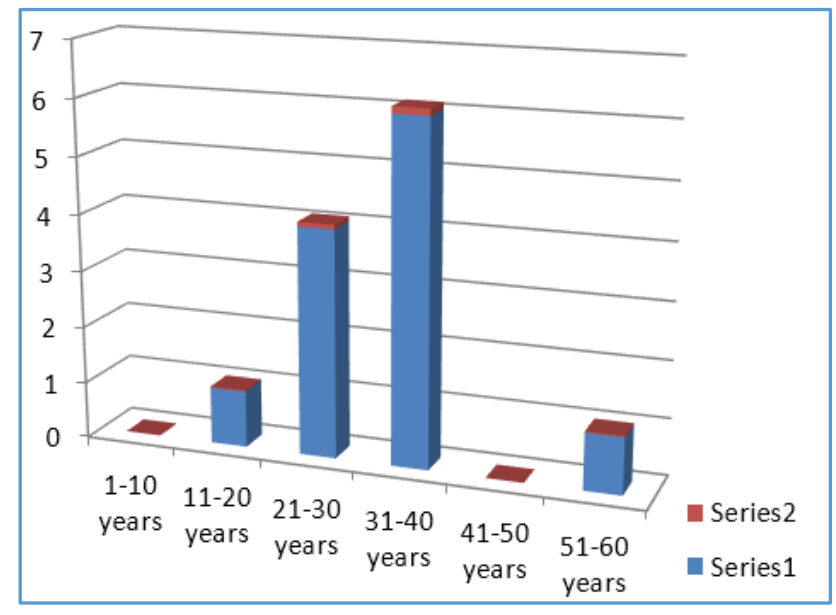

\begin{tabular}{|c|c|c|}
\hline Age Group & Sticker Bindi and Nickel & $\%$ \\
\hline $1-10$ years & 0 & $0 \%$ \\
\hline 11-20 years & 0 & $0 \%$ \\
\hline $21-30$ years & 1 & $2 \%$ \\
\hline $31-40$ years & 3 & $6 \%$ \\
\hline $41-50$ years & 2 & $4 \%$ \\
\hline $51-60$ years & 0 & $0 \%$ \\
\hline Total & 6 & $12 \%$ \\
\hline \multicolumn{3}{|c|}{$\begin{array}{c}\text { Table 5. Age Distribution of Positive } \\
\text { Cases for Sticker Bindi and Nickel }\end{array}$} \\
\hline
\end{tabular}

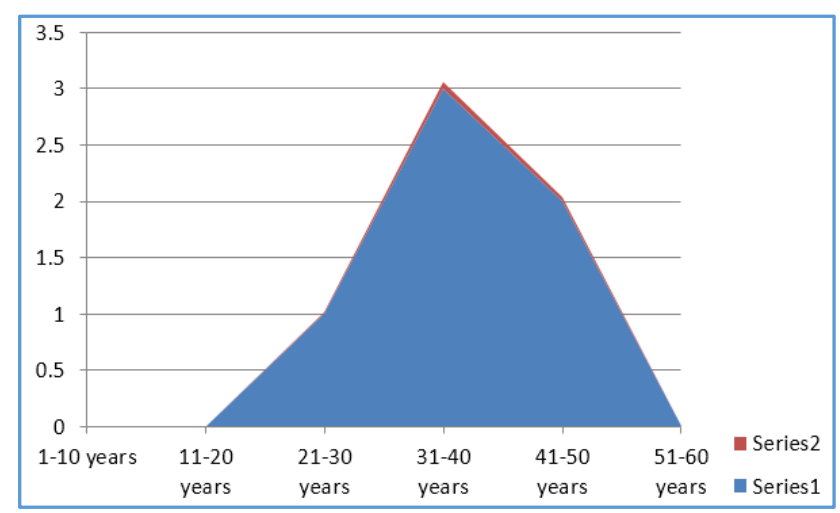

\begin{tabular}{|c|c|}
\hline $\begin{array}{l}\text { Duration of } \\
\text { Application }\end{array}$ & $\begin{array}{l}\text { Development of Dermatitis } \\
\text { in Patients (Lag Period) }\end{array}$ \\
\hline $1-10$ years & 2 \\
\hline $11-20$ years & 4 \\
\hline $21-30$ years & 12 \\
\hline $31-40$ years & 15 \\
\hline 41-50 years & 3 \\
\hline 51-60 years & 2 \\
\hline Total & 38 \\
\hline \multicolumn{2}{|c|}{$\begin{array}{c}\text { Table 6. Duration of Application of Kumkum, Sticker } \\
\text { Bindi and Development of Dermatitis }\end{array}$} \\
\hline
\end{tabular}

\begin{tabular}{|c|c|c|}
\hline No. of Patients & Patch Test Reading & Percentage \\
\hline 4 & + & $8 \%$ \\
\hline 13 & ++ & $26 \%$ \\
\hline 3 & +++ & $6 \%$ \\
\hline 20 & & \\
\hline \multicolumn{2}{|c|}{ Table 7. Patch Test Reading in Patients } \\
Positive for Kumkum and Turmeric \\
\hline
\end{tabular}

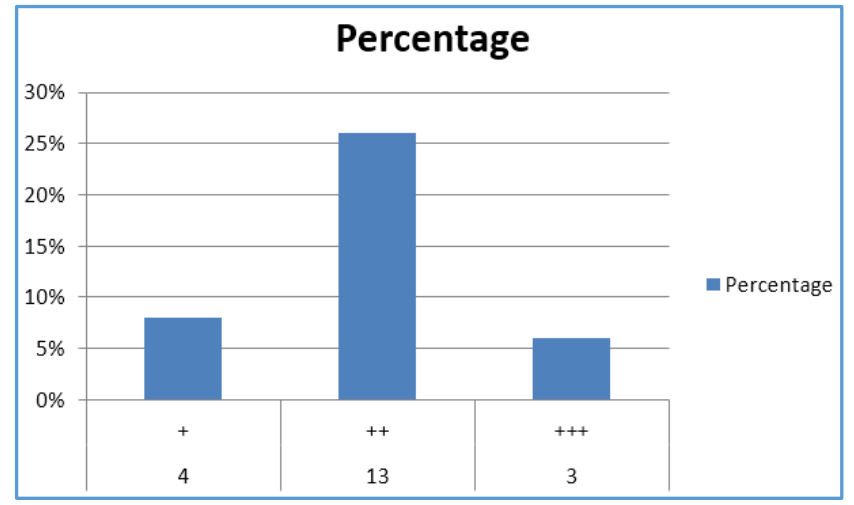

\begin{tabular}{|c|c|c|}
\hline No. of Patients & Patch Test Reading & Percentage \\
\hline 3 & + & $6 \%$ \\
\hline 6 & ++ & $12 \%$ \\
\hline 3 & +++ & $6 \%$ \\
\hline 12 & & \\
\hline $\begin{array}{r}\text { Table 8. Patch Test reading in Patients Positive for } \\
\text { Kumkum, Turmeric, Sticker Bindi and Nickel }\end{array}$ \\
\hline
\end{tabular}

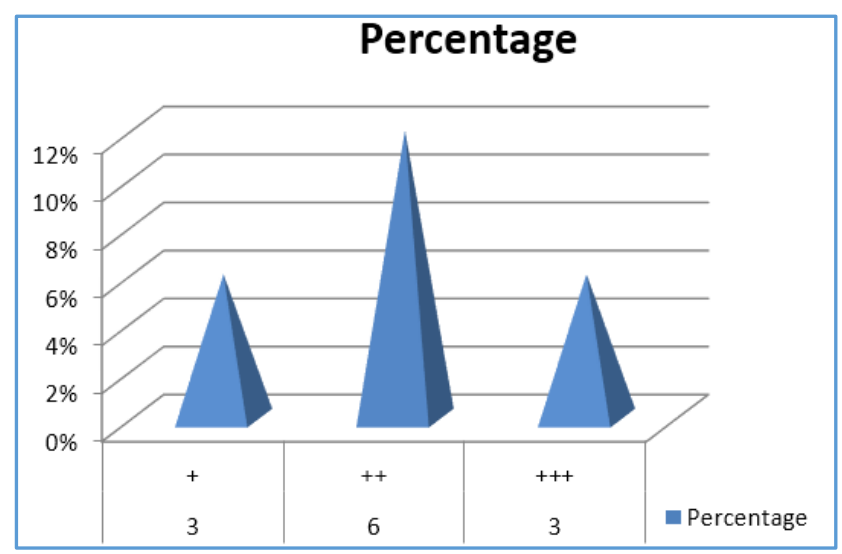

\begin{tabular}{|c|c|c|}
\hline No. of Patients & Patch Test Reading & Percentage \\
\hline 1 & + & $2 \%$ \\
\hline 3 & ++ & $6 \%$ \\
\hline 2 & +++ & $4 \%$ \\
\hline 6 & & \\
\hline \multicolumn{2}{|c|}{ Table 9. Patch Test Reading in Patients Positive } \\
for Sticker Bindi and Nickel \\
\hline
\end{tabular}





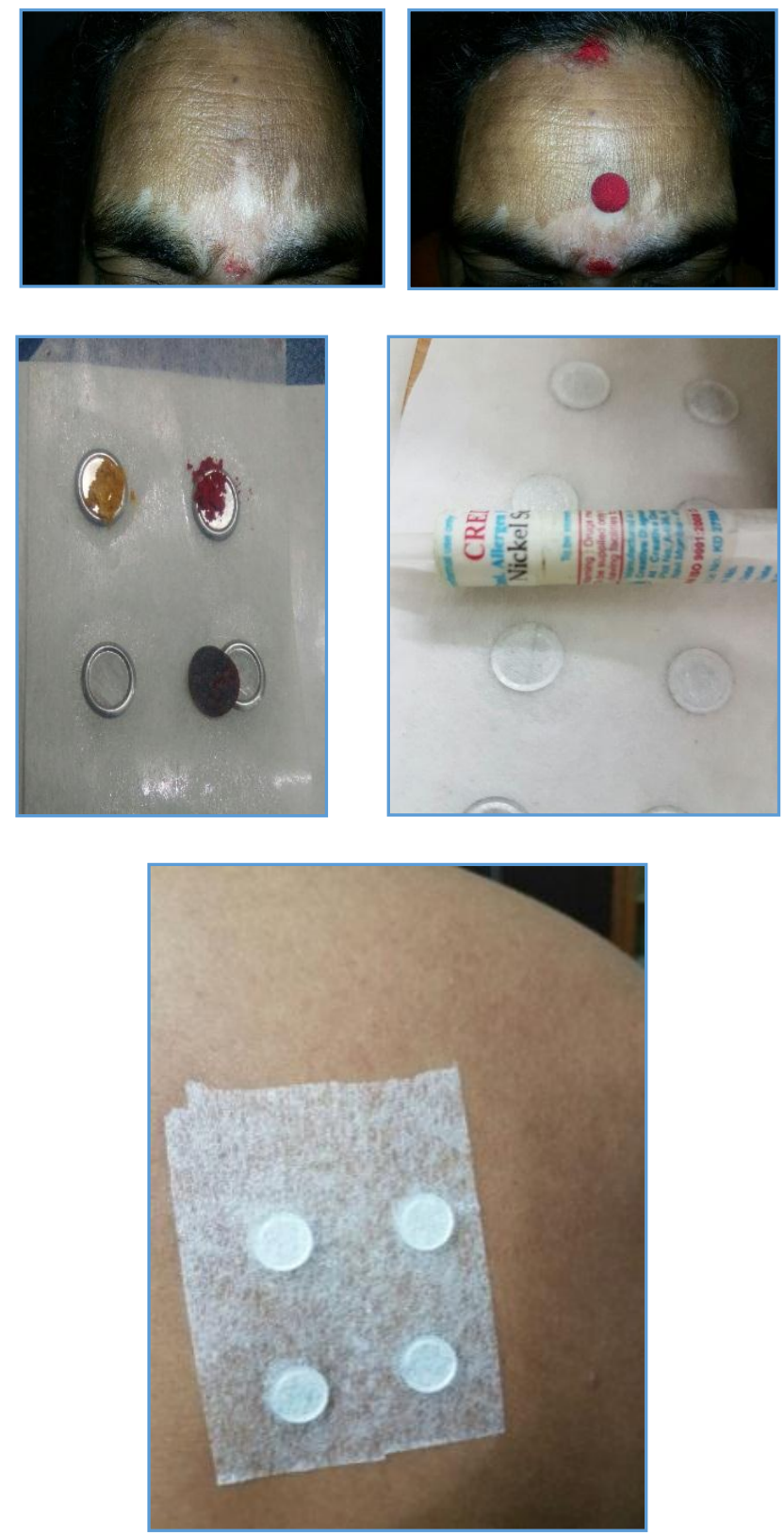

\section{Patch Testing with Kumkum, Sticker Bindi, Extracted Turmeric Allergen, Nickel}

\section{DISCUSSION}

This prospective clinical study was conducted to evaluate dermatitis (Allergic contact dermatitis) due to kumkum, sticker bindi and to conform the allergen in kumkum and sticker bindi. Out of 50 patients tested, we found 20 (40\%) cases positive for kumkum and turmeric, 12 (24\%) cases positive for kumkum, sticker bindi, turmeric and Nickel and 6 (12\%) patients for sticker bindi and Nickel. The overall kumkum and turmeric positive cases are 32 (64\%), and the overall bindi and nickel positive cases are 18 (36\%) which are said to be statistically significant.

Allergic contact dermatitis to turmeric in kumkum has been reported. Kumkum is made by mixing turmeric powder with small amounts of lime. A 43-year-old female developed dermatitis after the application of kumkum, she also complained of minimal itching over the face following application of turmeric paste, made by grinding the raw turmeric on a rough surface with few drops of water. She was patch tested with turmeric on a rough surface with a few drops of water. She was patch tested with turmeric, to which she developed positive reaction. Subsequently, she was patch tested with acetone extract and precipitate of the powder. It was concluded that allergy was due to turmeric present in kumkum.15

Kumkum is a commonly used cosmetic in India, traditionally based on turmeric powder, and its ingredients can cause various types of dermatoses. Patch testing with kumkum was positive in 7 of 13 patients tested. ${ }^{16}$

In our study, we have also demonstrated allergic contact dermatitis to turmeric in kumkum and is in accordance with the above two studies.

Nickel in sticker bindi can cause allergic contact dermatitis.11 In our study, we have shown relevant patch testing in patients who are using sticker bindi and is in accordance with the above study.

The maximum number of positive cases for kumkum and turmeric are seen in the age group of 21 to 30 years and the maximum number of the positive cases for kumkum, turmeric, sticker bindi and nickel are seen in the age group of 31 to 40 years and for sticker bindi and nickel in the age group of 31 to 40 years. In the majority of patients 15 (30\%), the time interval between application of kumkum and bindi and development of dermatitis is 31 to 40 years which means there is huge lag period for sensitisation to occur for the allergen.

Due to wide use of turmeric for its cosmetic benefits, medicinal properties, traditional beliefs in day-to-day life, there can be a high sensitising potential for turmeric as a result of which turmeric in kumkum can cause dermatitis. In our study, when compared to kumkum and bindi the positive results are more for kumkum (more allergenic).

Females get exposed to nickel since childhood mainly in the form of ornaments and is again one of the most common allergen which causes allergic contact dermatitis in females. Application of kumkum and sticker bindi is inevitable for Hindu women and despite of dermatitis, Hindu women continue applying kumkum and sticker bindi to live up to their traditional beliefs. In this situations, a remedy, that is heated and dried kumkum which is non-allergenic is recommended for kumkum. ${ }^{15}$ Sikta taila which is prepared by mixing and heating one part of beewax with five parts of sesame oil and filtered can be applied and over it sticker bindi can be placed which can prevent dermatitis.

In our study, the dermatitis was relevant as proved with patch testing in $38(76 \%)$ patients and statistically significant. Apart from turmeric in kumkum, the other ingredients in kumkum are Brilliant lake red R, Sudan I, aminobenzenes and Cananga oil. Allergy to these ingredients are reported.17-21 Bindi dermatitis due to thimerosal and gallate mix has also been reported. 12

\section{CONCLUSION}

According to our study, turmeric in kumkum and nickel in bindi are the main allergens as shown relevant by patch testing. In patients who are patch test negative for turmeric and nickel (12 patients), the other ingredients of turmeric and bindi are also needed to be tested as mentioned in the above studies. 


\section{REFERENCES}

1. Pasricha JS. Contact dermatitis in India. $2^{\text {nd }}$ edn. New Delhi: The Off Setters 1988:67-85.

2. Kumkum. Wikipedia, the free encyclopedia. 2008. URL: http://en.wikipedia.org/wiki/kumkum.

3. Ravindran PN. Turmeric. The golden spice of life. In: Ravindran PN, Babu KN, Sivaram K. eds. Turmeric. The Genus Curcuma. Boca Raton, Fl, USA: CRC Press 2007:115.

4. Anticancer potential of Turmeric. Alternative medicine Alert 2003.

5. Marmion DN. Hand book of US colorants. Foods, drugs, cosmetics and medical devices. $3^{\text {rd }}$ edn. New York: John Wiley and Sons 1991.

6. Mathur AK, Srivastava AK, Singh A, et al. Contact depigmentation by adhesive material of bindi. Contact Dermatitis 1991;24(4):310-1.

7. Ghosh S, Mukhopadhyay S. Chemical leucoderma: a clinico-aetiological study of 864 cases in the perspective of a developing country. Br J Dermatol 2009;160(1):407.

8. Bajaj AK, Gupta SC, Chatterjee AK. Contact depigmentation from free para-tertiary-butyl phenol in bindi adhesive. Contact Dermatitis 1990;22(2):99-102.

9. Calnan CD, Cooke MA. Leukoderma in industry. J Soc Occup Med 1974;24(2):59-61.

10. Dwyer CM, Forsyth A. Allergic contact dermatitis from bindi. Contact Dermatitis 1994;30(3):174.

11. Baxter KF, Wilkinson SM. Contact dermatitis from a nickel-containing bindi. Contact Dermatitis 2002;47(1):55.
12. Laxmisha C, Nath AK, Thappa DM. Bindi dermatitis due to thimerosal and gallate mix. J Eur Acad Dermatol Venereol 2006;20(10):1370-2.

13. Bajaj AK, Govil DC. Contact depigmentation. Indian J Dermatol Venereol Leprol 1982;48:112-5.

14. Bajaj AK, Govil DC, Bajaj S. Bindi depigmentation. Arch Dermatol 1983;119(18):629.

15. Lal SMB, Srinivas CR. Allergic contact dermatitis to turmeric in kumkum. Indian Journal of Dermatology 2006;51(3):200-1.

16. Nath Ak, Thappa DM. Kumkum- induced dermatitis: an analysis of 46 cases. Clin Exp Dermatol 2007;32(4):3857.

17. Kumar JV, Raeeq M, Murgesh SB. Contactants in "KumKum" dermatitis. Indian J Dermatol Venereol Leprol 1996;62(4):220-21.

18. Nath AK, Thappa DM. Clinical spectrum of dermatoses caused by cosmetics in south India: high prevalence of kumkum dermatitis. Indian J Dermatol Venereol Leprol 2007;73(3):195-6.

19. Kozuka I, Goh CL, Doi T, et al. Sudan I as a cause of pigmented contact dermatitis In "kumkum" (an Indian cosmetic). Ann Acad Med Singapore 1988;17(4):492-4.

20. Kozuka T, Tashiro M, Sano S, et al. Brilliant Lake Red R as a cause of pigmented contact dermatitis. Contact Dermatitis 1979;5(5):297-304.

21. Kozuka T, Tashiro M, Sano S, et al. Pigmented contact dermatitis from azo dyes. I. Cross-Sensitivity in humans. Contact Dermatitis 1980;6(5):330-6. 